\title{
The 'broken heart' syndrome
}

\author{
What can be learned from the tears and distress?
}

\author{
M.J.M. Cramer, B. De Boeck, P.G. Melman, G-J. Sieswerda
}

Il pleure dans mon coeur

Comme il pleut sur la ville;

Quelle est cette langueur

Qui pénètre mon coeur?

Paul Verlaine (1844 - 1896)

\section{Tako-tsubo-like left ventricular dysfunction}

It is not very often that a novel cardiac syndrome provokes such a great interest from cardiologists worldwide. In 1991, cardiologists from Hiroshima, Japan were the first to report a cardiac syndrome with female preponderance exhibiting transient left ventricular apical ballooning, electrocardiographic changes, and minimal myocardial enzymatic release mimicking acute myocardial infarction without significant epicardial coronary artery disease. ${ }^{1}$ The cardiologists from the Hiroshima City Hospital originally proposed the term tako-tsubo-like left ventricular dysfunction, because the typical shape on end-systolic left ventriculogram resembles a tako-tsubo (octopus trap) with a round (akinetic) apex and narrow (hyperkinetic) base. Based on the first series of 30 patients from this group, published ten years later, they believed that simultaneous multivessel coronary spasm was one of the main causes. ${ }^{2}$ Of note, in their series of 30 patients acute coronary angiography revealed no coronary artery disease in 25 patients, and only moderate single coronary artery disease in five patients. Three patients showed spontaneous multivessel coronary spasm. In ten patients, coronary spasm could be provoked by either

M.J.M. Cramer

B. De Boeck

P.G. Melman

G-J. Sieswerda

Department of Non-Invasive Cardiac Imaging, University Medical

Centre Utrecht, Utrecht, the Netherlands

Correspondence to: M.J.M. Cramer

Department of Non-Invasive Cardiac Imaging, University Medical Centre Utrecht, PO Box 85500, 3508 GA Utrecht, the Netherlands

E-mail: m.j.m.cramer@umcutrecht.nl ergonovine or acetylcholine. ${ }^{2}$ Vasospastic ischaemia is supposed to be more common in Japan than in the rest of the world. ${ }^{3}$

\section{The broken heart syndrome}

Fifteen years later, two almost simultaneously published papers in the New England Journal ${ }^{4}$ and Circulation $^{5}$ demonstrated that this syndrome was not confined to Japanese patients. These reports reconfirmed that profound (psychological) stress was the main clinical scenario of this acute but rapidly reversible left ventricular systolic dysfunction and that it mainly occurred in the hearts of older, postmenopausal women. Their tears and pain are the same, but the stress factor covers the full spectrum of the emotional domain. After these two seminal publications, stressinduced cardiomyopathy was recognised all over the world. The public press also got hold of the news that the folkloric myth of the broken heart was finally scientifically proven: 'A woman's heart can be broken, but given proper attention a broken heart can be mended!'

Why it has taken science so long to discover what folklore has recognised for centuries is probably due to the fact that immediate coronary angiography in ST-segment elevation acute coronary syndromes only became standard practice a few years ago. While in the thrombolytic era the clinical picture would have been characterised as 'successful thrombolysis', nowadays, when one is faced with normal coronary arteries, a reversible stress cardiomyopathy should be suspected and ruled out by a left ventriculogram or noninvasive imaging techniques.

In this Journal, interesting cases from Enschede and Maastricht, the Netherlands are presented. ${ }^{6,7}$ The first article demonstrates the characteristic features by MRI, the second article by echocardiographic imaging. In the Netherlands, R. Michels and colleagues from Eindhoven were the first to report myocardial bridging associated with takotsubo syndrome (TTS) and the first to report of TTS associated with dynamic left ventricular outflow tract obstruction with systolic anterior motion and mitral regurgitation. ${ }^{8}$ 


\section{From ischaemia-mediated stunning to 'scary sigmoid septum'}

The three most characteristic features of this syndrome are the reversible nature of the extensive but local wall motion abnormalities, the apparent provocation by (emotional) stress and the female predominance. The first-mentioned characteristic resembles myocardial stunning, a condition caused by transient ischaemia. The link with stress suggests an exaggerated sympathetic stimulation, a concept that was substantiated by the study by Wittstein demonstrating that plasma catecholamine levels at presentation were markedly higher among patients with stress-induced cardiomyopathy than among those with Killip class III myocardial infarction. ${ }^{4}$ More evidence for an exaggerated sympathetic stimulation or sensitivity and for the preference of this entity to distress the hearts of women has come from studies in ovariectomised female rats in which the syndrome of local apical ballooning provoked by restraining stress could be prevented by $\beta$ blockade and attenuated by oestrogen suppletion., ${ }^{9,10}$ Emotional stress induces transient left ventricular hypocontraction in the rat via activation of cardiac adrenoceptors: a possible animal model of takotsubo cardiomyopathy. Oestrogen attenuates the emotional stress-induced cardiac responses in the animal model of takotsubo (ampulla) cardiomyopathy. However, the exact mechanism of this sympathetically mediated dysfunction resembling myocardial stunning is not known. Ischaemia resulting from epicardial coronary spasm or microvascular spasm has been postulated as a causative mechanism. Another putative mechanism would be a direct catecholamine-mediated myocyte injury. This results in a transient metabolic knock-out with an impaired glucose and fatty acid metabolism uncommon to stunning caused by ischaemia ${ }^{11}$ and is accompanied by an apparent neuronal knock-out or functional denervation as well. ${ }^{12}$

What remains is the question why the myocardial affliction is localised in this entity. An explanation for apical affliction would be that the distal (apical) myocardium is considered most vulnerable to adrenergic aggression, ${ }^{13}$ also suggested by a similar distribution of left ventricular wall motion abnormalities in pheochromocytoma-related cardiomyopathy. ${ }^{3}$ However, recently several other forms have been described..$^{14-16}$ Therefore, several types can now be described (table 1). Finally, the reason for the much more common occurrence in post-menopausal women is also unclear.

Table 1. Transient ventricular cardiomyopathies. ${ }^{20}$

Type I Apical ballooning takotsubo cardiomyopathy

Type II Mid-ventricular ballooning

Type III Apical sparing cardiomyopathy

Type IV Basal ballooning

Type V Other segmental involvement
Sex hormones may have an influence on vasoreactivity and the neurohumoral axis. Elderly women are also known to develop abnormal basal thickening (sigmoid septum). A dynamic left ventricular outflow tract obstruction provoked during dobutamine stress ${ }^{17}$ has also been observed in patients with healed takotsubo syndrome (personal communication P.G. Melman). A severe transient left ventricular mid-cavity obstruction, caused by an abnormal myocardial architecture in the presence of dehydration and raised catecholamine levels following physical or emotional stress, has been put forward as a new theory. This subdivides the left ventricle into two functionally different chambers with a marked increase in wall stress in the high pressure distal chamber. With rehydration / fall in catecholamine levels the gradient resolves and distal function recovers. ${ }^{18}$ Hopefully, the SEAS Study (Serial Echocardiography After Subarachnoid haemorrhage) evaluating cardiac abnormalities using subarachnoid haemorrhage as a model for sympathetic stress will shed more light on the pathophysiological mechanism of the 'broken heart' syndrome. ${ }^{19}$

\section{To end the affaire}

\section{For daily clinical practice}

In case of an acute coronary syndrome with normal coronary arteries, perform a left ventriculogram, or assess left ventricular function by noninvasive techniques. Admit the patient for monitoring because death due to ventricular rupture or fibrillation can occur in the acute phase. Rule out a subarachnoidal haemorrhage or other high catecholamine states such as a pheochromocytoma. Check for dehydration and after further conservative management, check for a sigmoid septum and advise ample hydration in stressful situations to avoid another 'broken heart'. The role of (low-dose) $\beta$-blockade in the treatment of TTS is a point of discussion and warrants further investigation.

\section{References}

l Dote K, Sato H, Tateishi H, et al. Myocardial stunning due to simultaneous multivessel coronary spasm: a review of 5 cases. $J$ Cardiol 1991;21:203-14.

2 Kurisu S, Sato H, Kawagoe T, Ishihara M, Shimatani Y, Nishioka $\mathrm{K}$, et al. Tako-Tsubo-like left ventricular dysfunction with STsegment elevation: A novel cardiac syndrome mimicking acute myocardial infarction. Am Heart J 2002;143:448-55.

3 Gianni M, Dentali F, Grandi AM, Sumner G, Hiralal R, Lonn E. Apical ballooning syndrome of takotsubo cardiomyopathy: a systematic review. Eur Heart J 2006;27:1523-9.

4 Wittstein HS, Thiemann DR, Lima JAC, Baughman KL, Schulman SP, Gerstenblith G, et al. Neurohumoral features of myocardial stunning due to sudden emotional stress. New Engl J Med 2005;352:539-48.

5 Sharkey SW, Lesser JR, Zenovich AG, Maron MS, Lindberg J, Longe TF, et al. Acute and reversible cardiomyopathy provoked by stress in women from the United States. Circulation 2005; 111:472-9.

6 Gurlek C, van Es J, van der Burgh PH, Galjee MA, van Birgelen C. Full pattern of transient apical ballooning of the left ventricle triggered by minor myocardial infarction. Neth Heart J 2007; 15:310-1. 
7 Van Opstal JM, Cheriex EC. Stress-induced cardiomyopathy. Neth Heart J 2007;15:312.

8 Michels R, Brueren G, van Dantzig J-M, Pijls N, Peels CH, Post H. ACS, myocardial bridging, Tako-Tsubo syndrome and mitral regurgitation. Neth Heart J 2005;13:57-61.

9 Ueyama T, Kasamatsu K, Hano T, Yamamoto K, Tsuruo Y, Nishio I. Emotional stress induces transient left ventricular hypocontraction in the rat via activation of cardiac adrenoceptors: a possible animal model of 'tako-tsubo' cardiomyopathy. Circ J 2002 66:712-3.

10 Ueyama T, Hano T, Kasamatsu K, Yamamoto K, Tsuruo Y, Nishio I. Oestrogen attenuates the emotional stress-induced cardiac responses in the animal model of Tako-tsubo (Ampulla) cardiomyopathy. J Cardiovasc Pharmacol 2003;42:S1 17-9.

11 De Boeck BWL, Verburg FA, Hobbelink MGG, Velthuis B, Melman PM, Cramer MJM. Reversible 18-FDG-uptake defects on myocardial PET: is this myocardial resurrection? Int J Cardiol 2007 (in press).

12 Scholte AJ, Bax JJ, Stokkel MP, Plokker T, Kaandorp TA, Lamb $\mathrm{HJ}$, et al. Multimodality imaging to diagnose takotsubo cardiomyopathy. J Nucl Cardiol 2006;13:123-6.

13 Mori H, Ishikawa S, Kojima S, Hayashi J, Watanabe Y, Hoffman II, et al. Increased responsiveness of left ventricular apical myocardium to adrenergic stimuli. Cardiovasc Res 1993;27:192-8.
14 Reuss CS, Lester SJ, Hurst RT, Askew JW, Nager P, Lusk J, et al. Isolated left ventricular Basal ballooning phenotype of transient cardiomyopathy in young women. Am J Cardiology 2007;99: 1451-3.

15 Steen H, Merten C, Katus HA, Giannitsis E. Images in cardiovascular medicine. A rare form of midventricular Tako-Tsubo after emotional stress followed up with magnetic resonance imaging. Circulation 2006;114:e248.

16 Abdulla I, Kay S, Mussap C, Nelson GI, Rasmussen HH, Hansen PS, et al. Apical sparing in Tako-Tsubo cardiomyopathy. Intern Med J 2006;36:414-8

17 Dawn B, Paliwal VS, Raza ST, Mastali K, Longaker RA, Stoddard MF. Left ventricular outflow tract obstruction provoked during dobutamine stress echocardiography predicts future chest pain, syncope, and near syncope. Am Heart J 2005;149:908-16.

18 Merli E, Sutcliffe S, Gori M, Sutherland GGR. Tako-Tsubo cardiomyopathy: new insights into the possible underlying pathophysiology. Eur J Echocardiography 2006;6:53-61.

19 Van der Bilt IAC, Hasan D, Rinkel GJE, Wilde AAM, Visser FC. Rationale of the SEAS Study. Neth Heart J2006;14:366-71.

20 Reeder GS. Stress-induced (Tako-Tsubo) cardiomyopathy. Mayo Foundation, April 2007 